\title{
Thomas Stephen Szasz (1920-2012)
}

Thomas Szasz was born in Budapest and immigrated to the USA with his Jewish parents in 1938. After completing a degree in physics and graduating in medicine in Cincinnati, he moved to Chicago in 1944 where he trained in psychiatry and psychoanalysis. Following a period with the US Navy he went to the State University of New York (SUNY), eventually receiving the chair of psychiatry at SUNY Health Science Center, Syracuse.

Szasz viewed mental health problems as problems in living rather than disorders since there was no consistent pathology as is found with neurological disease. His books (especially The Myth of Mental Illness, published in 1961) presented the view that psychiatrists pathologise patients so that they can be incarcerated. He argued that their behaviour is thereby 'managed' for the sake of social order. Szasz was a hugely influential figure to the liberal wing of the American legal profession. He was quoted widely in the successful campaign to reduce the avenues open to psychiatrists who believe a patient requires involuntary admission to hospital. Szasz did not want to see patients unless they wanted to see him.

A skilled writer, Szasz would pair an obviously odious historical event with involuntary admission of patients so that the latter became tarnished by association (e.g. The Manufacture of Madness: A Comparative Study of the Inquisition and the Mental Health Movement, published in 1970). He could also be amusing, as when he accepted a request by the undersigned to write an article on masturbatory insanity for the then Irish Journal of Psychotherapy (now the Irish Journal of Psychological Medicine).
Did Szasz do any good? There is much historical truth in the perception of American (and other) asylums as being overcrowded, poorly maintained, and open to abuses. If he had a unique role in changing this disgraceful situation he could be proud. He was, however, only one of many voices involved in this campaign.

Did he do harm? It is difficult to single out one person for denunciation, but Szasz was very influential. While he seems to have genuinely believed in the autonomy of patients, the reality is that he offered no viable alternatives to involuntary treatment.

The current high levels of untreated mental illness, homelessness, the exploding prison population, and the emphasis on rights rather than treatment needs can be traced in large measure to Szasz and his acolytes. Today, following a US Supreme Court decision (O'Connor v. Donaldson, 1975), one has to be an immediate threat in order to be detained as an involuntary patient. Take a walk down Mission Street in San Francisco for a real life illustration of the abandonment of people with mental illness, what Appelbaum and Gutheil1 referred to as "rotting with their rights on".

\section{Brian O'Shea FRCPsych}

Newcastle Hospital, Greystones, Co. Wicklow

Email: drbosheas@eircom.net

\footnotetext{
1. Appelbaum PS, Gutheil TG. "Rotting with their rights on": constitutional theory and clinical reality in drug refusal by psychiatric patients. Bull Am Acad Psychiatry Law 1979; 7: 306-315.
} 